\title{
Synthesis of Saponins Using Partially Protected Glycosyl Donors
}

\author{
Yuguo Du, ${ }^{*, \dagger}$ Guofeng Gu, ${ }^{\dagger}$ Guohua Wei, ${ }^{\dagger}$ Yuxia Hua, ${ }^{\dagger}$ and Robert J. Linhardt*,‡ \\ Research Center for Eco-Environmental Sciences, Chinese Academy of Sciences, \\ Beijing 100085, China, and Departments of Chemistry, Biology, and Chemical and \\ Biological Engineering, Rensselaer Polytechnic Institute, Troy, New York 12180
}

duyuguo@mail.rcees.ac.cn; linhar@rpi.edu

Received July 21, 2003

\section{ABSTRACT}

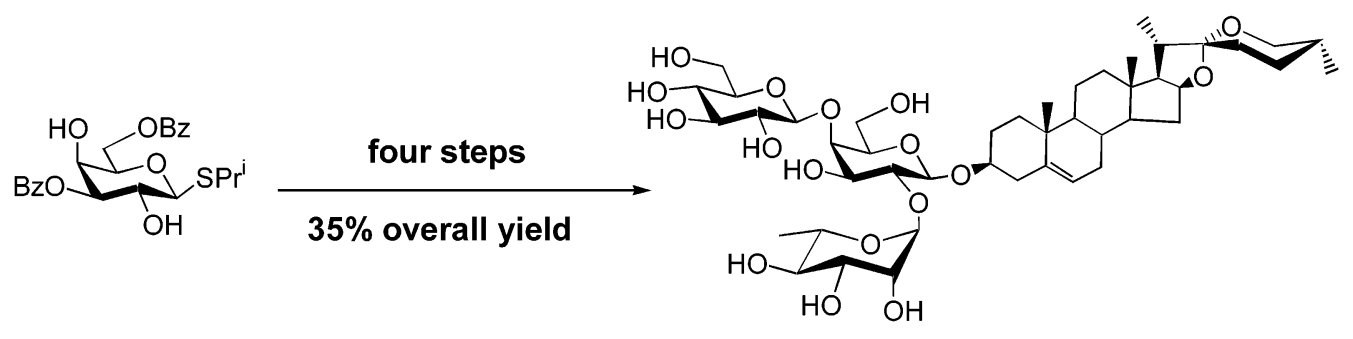

A new class of glycosyl donors having unprotected 2- and 2,4-hydroxyl groups were investigated under the standard glycosylation conditions. This approach was shown to be generally effective for the synthesis of alkyl and steroidal glycosides. A natural saponin, containing 2,4branched oligosaccharide, was prepared in $35 \%$ overall yield in four straightforward sequential reactions by taking advantage of these partially protected donors.

Recent investigations in glycobiology have revealed important roles for many glycoconjugates in the immune response, viral and bacterial infection, cell regulation, differentiation, development, inflammation, cell adhesion, and many other inter- and intracellular communication processes. ${ }^{1}$ Saponins, a structurally and biologically diverse class of glycosides of steroids and triterpenes, are major components in traditional Chinese medicines and represent important examples of glycoconjugates with promising pharmaceutical and biological activities. ${ }^{2}$ Dioscin (diosgenyl 2,4-di- $O$ - $\alpha$-L-rhamnopyranosyl- $\beta$-D-glucopyranoside), polyphyllin $\mathrm{D}$ (diosgenyl $\alpha-\mathrm{L}-$ rhamno-pyranosyl-( $1 \rightarrow 2)$ - $[\alpha$-L-arabinofuranosyl- $(1 \rightarrow 4)]-\beta$ D-glucopyranoside), and balanitin 7 (diosgenyl $\alpha$-L-rhamnopyranosyl- $(1 \rightarrow 2)$ - $[\beta$-D-xylopyranosyl- $(1 \rightarrow 3)-\beta$-D-glucopyranosyl-( $1 \rightarrow 4)]-\beta$-D-gluco-pyranoside) display cardiovascular, antifungal, and antitumor activities. ${ }^{3}$ Moreover, the rhamnose moiety of solamargine (solasodinyl 2,4-di- $O$ - $\alpha$ -

\footnotetext{
Chinese Academy of Sciences.

$\doteqdot$ Rensselaer Polytechnic Institute.

(1) For reviews see: (a) Varki, A. Glycobiology 1993, 3, 97. (b) Lee, Y. C.; Lee, R. T. Acc. Chem. Res. 1995, 28, 321.

(2) Hostettmann, K.; Marston, A. Saponins; Cambridge University Press: New York, 1995.
}

L-rhamnopyranosyl- $\beta$-D-glucopyranoside) plays a crucial role in triggering cell death by apoptosis. ${ }^{4}$ These bioactive saponins are comprised of a 2,4-branched oligosaccharide moiety, as are $\mathrm{N}$-linked oligosaccharides and many plant polysaccharides. ${ }^{5}$ Thus, because of their biological functions and also their unique 2,4-dibranched chain structures, the efficient synthesis of these steroidal glycosides deserves extensive exploration.

Substantial effort has been devoted to the development of novel glycosylation reactions as strategies to access natural glycoconjugate structures. ${ }^{6}$ Saponins, having 2,4-branched oligosaccharides, have been traditionally assembled in three ways. $^{7}$ In the first approach, the reducing end sugar unit is coupled to the $\mathrm{C}-3$ of a steroid or triterpene, next protection group manipulation is performed on the sugar residue, usually

(3) (a) Nakano, K.; Murakami, K.; Takaishi, Y.; Tomimatsu, T.; Nohara, T. Chem. Pharm. Bull. 1989, 37, 116. (b) Hufford, C. D.; Liu, S.; Clark, A. M. J. Nat. Prod. 1988, 51, 94. (c) Liu, C.; Chen, Y. Acta Pharm. Sinica 1984, 19, 799. (d) Namba, T.; Huang, X.; Shu, Y.; Huang, S.; Hattoti, M.; Kakiuchi, N.; Wang, Q.; Xu, G. Planta Med. 1989, 55, 501. (e) Zhou, J. Pure Appl. Chem. 1989, 61, 457.

(4) Chang, L.-C.; Tsai, T.-R.; Wang, J.-J.; Lin, C.-N.; Kuo, K.-W. Biochem. Biophys. Res. Commun. 1998, 242, 21. 
4,6-benzylidination followed by blocking the 3-hydroxyl group to give the glycosyl acceptor containing a free 2-hydroxyl group. Glycosylation at this 2-hydroxyl group, followed by selective opening of the 4,6-benzylidene, affords a free 4-hydroxyl group, which is further glycosylated to furnish a 2,4-branched saponin. The disadvantages of this method are that it involves a lengthy and low-efficiency synthesis. This is especially problematic when the aglycone is expensive or available only in limited quantities. In the second approach, a more highly convergent synthesis of saponin is carried out using a suitably modified monosaccharide donor with a participatory $\mathrm{C}-2$ acyl protecting group to ensure the $\beta$-bond formation. However, the subsequent removal of C-2 acyl protecting groups from saponin derivatives, to expose the free 2-hydroxyl group for glycosylation, can be difficult. ${ }^{7 d}$ In the third approach, the 2,4-branched oligosaccharide is first prepared and then condensed with aglycone in the final step. Unfortunately, glycosylation with such an oligosaccharide results in decreased neighboring group participation and often generates $\alpha, \beta$-mixtures. ${ }^{7 \mathrm{~g}}$ With these difficulties in mind, we speculated that a partially protected glycosyl donor could be used to shorten the total synthesis of saponins. ${ }^{8}$

Model studies were first carried out on the preparation of alkyl glycosides using partially protected sugar donors and alkyl alcohol acceptors (Table 1) in $\mathrm{CH}_{2} \mathrm{Cl}_{2}$ at $-42{ }^{\circ} \mathrm{C}$ under

Table 1. Alkyl Glycoside Synthesis Using Partially Protected Glycosyl Donor

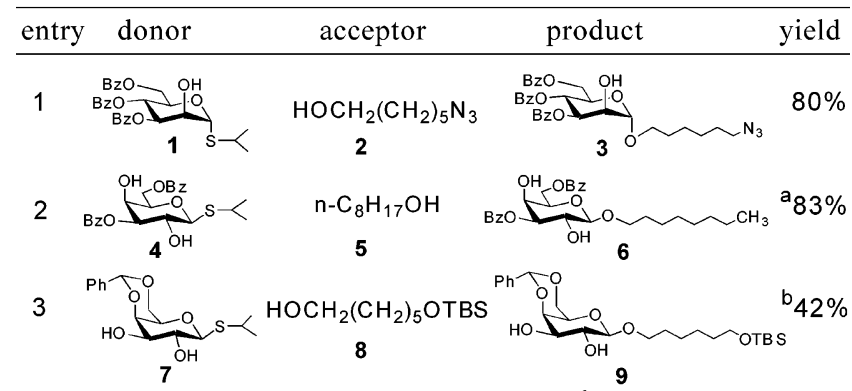

${ }^{a}$ A $7 \%$ yield of $\alpha$ isomer was also isolated. ${ }^{b}$ Including $32 \%$ of the $\beta$-isomer and $10 \%$ of the $\alpha$-isomer.

promotion with $\mathrm{N}$-iodosuccinimide (NIS) and trimethylsilyl trifluoromethanesulfate (TMSOTf). We were pleased to discover that mannopyranosyl thioglycoside 1, containing an unprotected hydroxyl group on C-2, still acted as an excellent glycosyl donor to afford $\alpha$-glycoside $\mathbf{3}$ in high yield (80\%).

No trace of self-condensed disaccharide was detected in our experiments. More impressively, when the galactopy-

(5) (a) Iorizzi, M.; De Marino, S.; Zollo, F. Curr. Org. Chem. 2001, 5, 951. (b) Bedir, E.; Khan, I. A. J. Nat. Prod. 2000, 63, 1699. (c) Yin, J.; Kouda, K.; Tezuka, Y.; Le Tran, Q.; Miyahara, T.; Chen, Y.; Kadota, S. J. Nat. Prod. 2003, 66, 646. (d) Nakamura, T.; Komori, C.; Lee, Y.-Y.; Hashimoto, F.; Yahara, S.; Nohara, T.; Ejima, A. Biol. Pharm. Bull. 1996, 19, 564. (e) Miyamura, M.; Nakano, K.; Nohara, T.; Tomimatsu, T.; Kawasaki, T. Chem. Pharm. Bull. 1982, 30, 712. (f) Akhov, L. S.; Musienko, M. M.; Piacente, S.; Pizza, C.; Oleszek, W. J. Agric. Food Chem. 1999, 47, 3193. (g) Dwek, R. A. Chem. Rev. 1996, 96, 683.

(6) For reviews, see: (a) Toshima, K.; Tasuta, K. Chem. Rev. 1993, 93, 1503. (b) Schmidt, R. R.; Kinzy, W. Adv. Carbohydr. Chem. Biochem. 1994 50, 21. (c) Garegg, P. J. Adv. Carbohydr. Chem. Biochem. 1997, 52, 179.
Table 2. Saponin Synthesis Using Partially Protected Glycosyl Donors

2 entry donor

${ }^{a}$ An additional $6 \%$ of the $\alpha$-isomer was isolated. ${ }^{b} \alpha: \beta=1: 2 .{ }^{c} \alpha: \beta=$ 2:3. ${ }^{d}$ An additional $14 \%$ yield of the disaccharide saponin derivative was also isolated.

ranosyl thioglycoside donor 4, containing 2,4-dihydroxyl groups, was subjected to similar reaction conditions, octyl $\beta$-D-galactopyranoside 6 was obtained in a yield of $83 \%(\alpha$ : $\beta=10: 1)$. Furthermore, 2,3-dihydroxyl donor 7 afforded a modest $(42 \%)$ yield of galactopyranoside 9 as a $1: 3 \alpha / \beta$ mixture. ${ }^{9}$

Encouraged by these preliminary results, we next turned our attention to saponin synthesis (Table 2). Condensation of donor $\mathbf{4}$ with diosgenin $\mathbf{1 0}$ in $\mathrm{CH}_{2} \mathrm{Cl}_{2}$ at $-42{ }^{\circ} \mathrm{C}$ under NIS-TMSOTf promotion afforded a $54 \%$ isolated yield of $\beta$-glycoside 11. A doublet at $4.53 \mathrm{ppm}(J=7.7 \mathrm{~Hz})$ in ${ }^{1} \mathrm{H}$ NMR spectrum clearly demonstrated the pure $\beta$-configuration

(7) (a) Lahmann, M.; Gybäck, H.; Garegg, P. J.; Oscarson, S.; Suhr, R.; Thiem, J. Carbohydr. Res. 2002, 337, 2153. (b) Yu, H.; Yu, B.; Wu, X.; Hui, Y.; Han, X. J. Chem. Soc., Perkin Trans. 1 2000, 1445. (c) Cheng, M.; Wang, Q.; Tian, Q.; Song, H.; Liu, Y.; Li, Q.; Xu, X.; Miao, H.; Yao, X.; Yang, Z. J. Org. Chem. 2003, 68, 3658. (d) Deng, S.; Yu, B.; Hui, Y.; Yu, B.; Han, X. Carbohydr. Res. 1999, 317, 53. (e) Deng, S.; Yu, B.; Hui, Y. Tetrahedron Lett. 1998, 39, 6511. (f) Li, B.; Yu, B.; Hui, Y.; Li, M.; Han, X.; Fung, K.-P. Carbohydr. Res. 2001, 331, 1. (g) Ikeda, T.; Miyashita, H.; Kajimoto, T.; Nohara, T. Tetrahedron Lett. 2001, 42, 2353.

(8) Plante, O.; Palmacci, E. R.; Andrade, R. B.; Seeberger, P. H. J. Am Chem. Soc. 2001, 123, 9545.

(9) General Procedure. To a mixture of thioglycosyl donor (1 mmol) and $\mathrm{ROH}(1 \mathrm{mmol})$ in anhydrous dichloromethane $(2 \mathrm{~mL})$ at $-42{ }^{\circ} \mathrm{C}$ were added $1.1 \mathrm{mmol}$ of NIS and catalytic amount of TMSOTf ( 0.1 equiv) with $\mathrm{N}_{2}$ protection. The reaction mixture was stirred under these conditions for $45 \mathrm{~min}$, at which time TLC indicated the completion of the reaction. The mixture was then neutralized with $\mathrm{Et}_{3} \mathrm{~N}$ and concentrated to dryness. The residue was subjected to column chromatography on silica gel with petroleum ether/EtOAc $(6 / 1-3 / 1)$ as the eluent to give the desired product. 
of $\mathbf{1 1}$. The $\alpha$-isomer might also be generated in this reaction, as the presence of inseparable contaminants did not permit us to rule out its formation. The 3,6-disilylated donor $\mathbf{1 2}$ gave an easily separable $\beta$-glycoside $\mathbf{1 3}$ (59\%), together with a $6 \%$ yield of the $\alpha$-product under the same reaction conditions. The 4,6-benzylidenated donor 7 produced a complex product mixture. In contrast, the corresponding C-3 protected donors $\mathbf{1 4}$ and $\mathbf{2 0}$ provided $\mathbf{1 5}$ and 22, respectively, in better yields and excellent regioselectivities, indicating that appropriate protection of the 3-hydroxyl group is critical for the effective application of this type of glycosyl donor. In parallel experiments, the stereochemical outcomes of 3,4isopropylidenated donors were greatly influenced by the substitution on C-6. For example, 6-silylated donor $\mathbf{2 3}$ gave cholesterol saponin 24 as an $\alpha, \beta$-mixture with low stereoselectivity, but 6-deoxy donor $\mathbf{2 5}$ afforded $45 \%$ yield of $\beta$-glycoside 26. When 2,4-unprotected glucosyl donor $\mathbf{1 6}$ was coupled with diosgenin $\mathbf{1 0}$ under the same reaction conditions, only a $36 \%$ yield of $\beta$-glycoside $\mathbf{1 7}$ was obtained, much lower than that obtained with the corresponding galactosyl donor 4. Interestingly, using a partially benzylated glucosyl donor $\mathbf{1 8}$ significantly improved the yield $(80 \%)$ and gave $\beta$-glycoside 19 as the sole product.

Coupling reactions between sugar residues were also investigated using thioglycoside donors with unprotected 2-hydroxyl or 2,4-hydroxyl groups (Table 3). When glucosyl

Table 3. Oligosaccharide Synthesis Using Partial Protected Glycosyl Donor

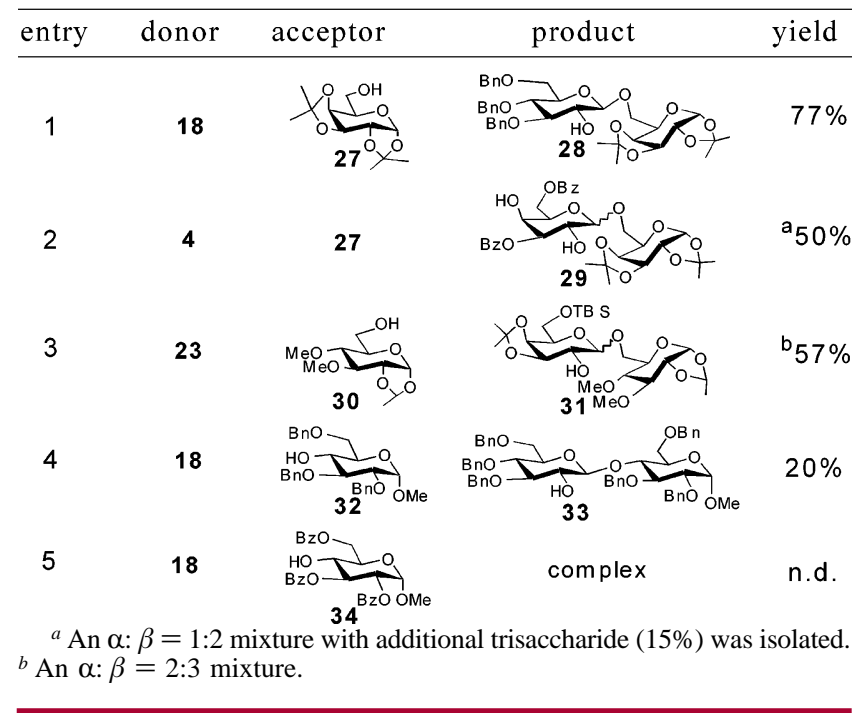

donor 18 was reacted with 1,2:3,4-di- $O$-isopropylidene- $\alpha$ D-galactopyranose (27) in $\mathrm{CH}_{2} \mathrm{Cl}_{2}$ at $-42{ }^{\circ} \mathrm{C}$ in the presence of NIS-TMSOTf, a 77\% yield of disaccharide $\mathbf{2 8}$ was isolated. However, a similar reaction between $\mathbf{4}$ and $\mathbf{2 7}$ gave only $50 \%$ yield of the $\alpha, \beta$-mixture 29. An inseparable $\alpha, \beta$ mixture of glycoside $31(\beta: \alpha=3: 2)$ was also obtained in $57 \%$ yield on glycosylation of $\mathbf{3 0}$ with $\mathbf{2 3}$. When sugar acceptors containing secondary hydroxyl groups (32 and $\mathbf{3 4}$ ) were examined, low yields or complex product mixtures were obtained (Table 3, entries 4 and 5).
The formation of the predominantly $\beta$-product can be rationalized as shown in Scheme $1 .{ }^{10}$ When glycosylation

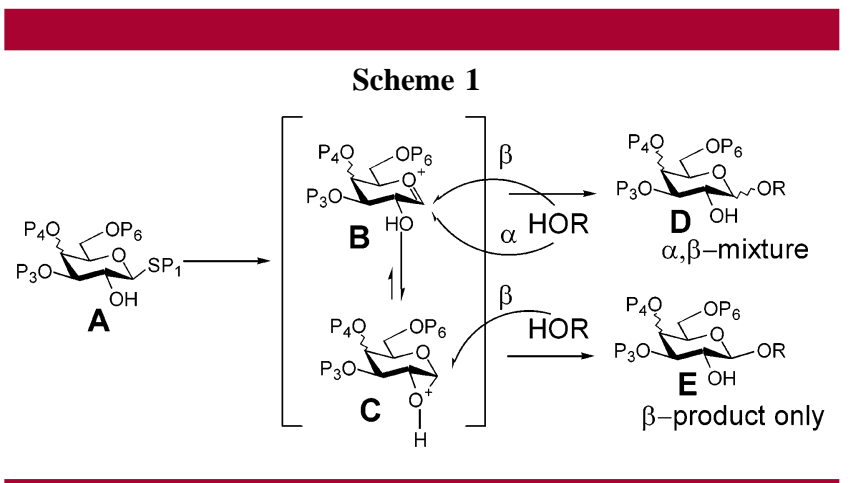

with thioglycoside $\mathbf{A}$ was promoted using NIS and TMSOTf, two reactive intermediates $\mathbf{B}$ and $\mathbf{C}$ could be generated. The 1,2-anhydrosugar intermediate $\mathbf{C}$ is formed through the intermolecular ring closure of $\mathbf{B}$. Stereoselective opening of intermediate $\mathbf{C}$ would afford $\beta$-product $\mathbf{E}$, while the $\alpha, \beta$ mixture $\mathbf{D}$ would be obtained through $\alpha$ - and $\beta$-attack on oxocarbenium $\mathbf{B}$.

To ascertain the efficiency of our new synthetic method, we next applied it to the synthesis of diosgenyl $\alpha$-Lrhamnopyranosyl-( $1 \rightarrow 2)$-[ $\beta$-D-glucopyranosyl- $(1 \rightarrow 4)]-\beta$-Dgalactopyranoside, ${ }^{5 \mathrm{f}}$ a potent drug candidate used to decrease the cholesterol level in serum.

Compound 4, containing unprotected 2,4-hydroxyl groups, was prepared from commercially available IPTG 35 according to the method described by Chan (Scheme 2). ${ }^{11}$ This

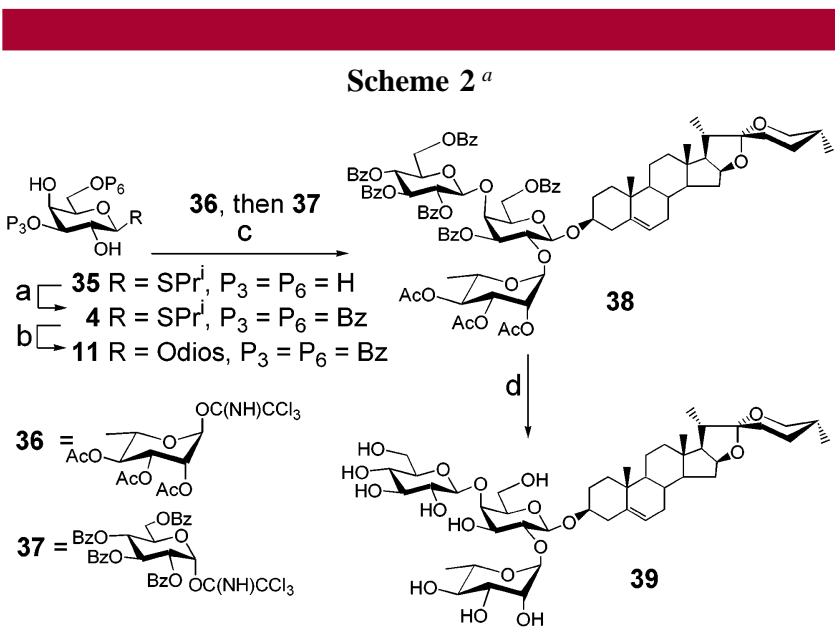

${ }^{a}$ Reaction conditions: (a) $\mathrm{BzCl}, \mathrm{Pyr},-10{ }^{\circ} \mathrm{C}, 70 \%$. (b) 10, NIS, TMSOTf, $\mathrm{CH}_{2} \mathrm{Cl}_{2},-42{ }^{\circ} \mathrm{C}, 54 \%$. (c) 36, TMSOTf, $\mathrm{CH}_{2} \mathrm{Cl}_{2},-42$ ${ }^{\circ} \mathrm{C}$; then 37, TMSOTf, $\mathrm{CH}_{2} \mathrm{Cl}_{2}, 0{ }^{\circ} \mathrm{C}, 68.7 \%$ for one-pot reaction. (d) Aqueous $1 \mathrm{~N} \mathrm{NaOH}, \mathrm{MeOH}, 95 \%$.

donor was condensed with diosgenin 10 in $\mathrm{CH}_{2} \mathrm{Cl}_{2}$ at -42 ${ }^{\circ} \mathrm{C}$ in the presence of NIS-TMSOTf, to afford the desired

(10) (a) Leeuwenburgh, M. A.; Timmers, C. M.; van der Marel, G. A.; van Boom, J. H.; Mallet, J.-M.; Sinaÿ, P. G. Tetrahedron Lett. 1997, 38, 6251. (b) Du, Y.; Kong, F. J. Carbohydr. Chem. 1995, 14, 341. 
$\beta$-glycoside $\mathbf{1 1}$ in $54 \%$ isolated yield. Compound $\mathbf{1 1}$ was glycosylated in one-pot with rhamnopyranosyl trichloroacetimidate 36 at $-42{ }^{\circ} \mathrm{C}$ in the presence of TMSOTf, followed by glucopyranosyl imidate 37 at $0{ }^{\circ} \mathrm{C}$, to afford the protected trisaccharide saponin derivative $\mathbf{3 8}$ (68.7\% from 11). Natural saponin 39 was then readily obtained by deacylation with aqueous $1 \mathrm{~N} \mathrm{NaOH}$ in $\mathrm{MeOH}$ (95\%). Remarkably, this complex natural saponin was prepared in four simple steps and in $35 \%$ overall yield.

In conclusion, an efficient and practical method has been developed for the preparation of saponins having 2,4branched oligosaccharide moieties. The key to this chemistry is the use of partially unprotected thioglycosides as glycosyl donors. This results in significantly simplified protecting group manipulation and oligosaccharide assembly. The approach described is general and effective for alkyl and

(11) Jiang, L.; Chan, T.-H. J. Org. Chem. 1998, 63, 6035. steroidal glycoside synthesis. More importantly, the application of this method with combinatorial chemistry might be useful as an efficient entry into libraries of more complex glycoconjugates. ${ }^{12}$

Acknowledgment. This work was supported by NNSF of China (29972053), RCEES of CAS, and NIH of the U.S. (HL62244).

Supporting Information Available: Preparation and physical data for compounds $3,6,9,11,13,15,17,19,22$, $\mathbf{2 6}, \mathbf{2 8}, \mathbf{2 9}, \mathbf{3 3}, \mathbf{3 8}$, and $\mathbf{3 9}$. This material is available free of charge via the Internet at http://pubs.acs.org.

OL035353S

(12) Marcaurelle, L. A.; Seeberger, P. H. Curr. Opin. Chem. Biol. 2002, 6, 289. 